\title{
Video Modeling and Video Feedback to Reduce Time to Perform Intravenous Cannulation in Medical Students: A Randomized- Controlled Mixed-Methods Study
}

\section{Vidéo de démonstration et vidéo de rétroaction pour réduire le temps de réalisation d'une canulation intraveineuse par des étudiants en médecine : une étude randomisée contrôlée de méthodes mixtes}

\author{
Julie Yu, MD, FRCPC (1) - Calvin Lo, MD, FRCPC • Claudia Madampage, PhD, MPH • \\ Jagmeet Bajwa, MSc • Jennifer O'Brien, PhD • Paul Olszynski, MD, CCFP-EM • \\ Malcolm Lucy, MD, FRCPC
}

Received: 29 August 2019/Revised: 16 December 2019/Accepted: 18 December 2020/Published online: 22 January 2020 (C) Canadian Anesthesiologists' Society 2020

\begin{abstract}
Purpose Combined video modeling (VM) and video feedback (VF) may be more beneficial than traditional feedback when teaching procedural skills. This study examined whether repeated VM and VF compared with
\end{abstract}

Poster presentation OHMES Health and Medical Education Symposium, February 22 2017, University of Calgary, Calgary, Alberta.

Oral presentation 30th Annual Resident Research Day, May 72017 , University of Saskatchewan, Saskatoon, Saskatchewan.

Oral presentation Medical Education Research and Scholarship Day, June 2 2017, College of Medicine, University of Saskatchewan, Saskatoon, Saskatchewan.

Electronic supplementary material The online version of this article (https://doi.org/10.1007/s12630-020-01570-2) contains supplementary material, which is available to authorized users.

J. Yu, MD, FRCPC $(\varangle) \cdot$ C. Lo, MD, FRCPC .

C. Madampage, PhD, MPH - J. Bajwa, MSc - J. O'Brien, PhD .

M. Lucy, MD, FRCPC

Department of Anesthesiology, Perioperative Medicine and Pain Management, Royal University Hospital, University of

Saskatchewan, G525-103 Hospital Drive, Saskatoon,

SK S7N 0W8, Canada

e-mail: julie.1.yu@gmail.com

P. Olszynski, MD, CCFP-EM

Department of Emergency Medicine, Royal University Hospital,

University of Saskatchewan, Saskatoon, SK, Canada
$V M$ alone reduced the time required for medical students to perform peripheral intravenous (IV) cannulation.

Methods Twenty-five novice medical students were randomly assigned to groups in a one-way blinded embedded mixed-methods study to perform IV cannulation. Participants received standardized instruction and performed IV cannulation on each other while being audio-video recorded. They were assigned to review a video of an expert performing IV cannulation (VM alone), or both the expert video and a video of their own most recent IV cannulation $(V M+V F)$, before returning to perform another IV cannulation. This was repeated for a total of four IV cannulation encounters and three video reviews. A post-test interview was also conducted and analyzed qualitatively using thematic content analysis.

Results The median [interquartile range] time required to perform IV cannulation in the final encounter was significantly different between the VM+VF group vs VM alone group (126 [93-226] sec vs 345 [131-537] sec, respectively; median difference, 111 sec; $95 \%$ confidence interval, 8 to 391; $P=0.02$ ). There was no significant difference in IV cannulation success between VM alone and $V M+V F$ in the final encounter $(75 \%$ vs $85 \%$ respectively; $P=0.65)$. For the $V M+V F$ group, the time to perform IV cannulation was reduced after the final encounter compared with the baseline encounter $(P=$ 0.002), which was not true of the VM alone group $(P=$ $0.35)$. 
Conclusion Video modeling and feedback shortened time to IV skill completion, reduced complications, and improved satisfaction in novice medical students.

\section{Résumé}

Objectif La combinaison d'une vidéo de démonstration (VD) et d'une vidéo de rétroaction (VR) pourrait être plus efficace que la rétroaction traditionnelle pour l'enseignement des habiletés nécessaires pour des procédures. Cette étude a cherché à savoir si la répétition d'une $V D$ et d'une $V R$ réduisait davantage le temps nécessaire à des étudiants en médecine pour effectuer une canulation intraveineuse périphérique (IV) par rapport à la seule VD.

Méthodes Vingt-cinq étudiants en médecine novices ont été assignés par randomisation à des groupes d'une étude utilisant différentes méthodes intégrées d'apprentissage avec insu unilatéral pour la réalisation d'une canulation IV. Les participants ont reçu un enseignement standardisé et ont réalisé une canulation IV sur un autre participant tout en étant filmés (audio-vidéo). Selon leur groupe, ils devaient visionner la vidéo d'un expert effectuant une canulation IV (groupe VD uniquement) ou voir la vidéo de l'expert et une vidéo de leur plus récente canulation IV (groupe VD $+V R$ ) avant d'effectuer une autre canulation IV. La procédure a été répétée (total de 4 tentatives de canulations et 3 séances de vidéos). Un entretien post test a été également mené et analysé du point de vue qualitatif au moyen d'une analyse thématique du contenu.

Résultats Le temps médian [plage interquartile] nécessaire pour effectuer la canulation IV au cours de la dernière tentative a été significativement différent entre le groupe VD+VR et le groupe VD seule (respectivement, 126 secondes [93 à $226 s$ ] contre $345 s$ [131 à 537 s]; différence des médianes, $111 \mathrm{~s}$; intervalle de confiance à $95 \%: 8$ à 391; $P=0,02$ ). Il n'y a pas eu de différence significative entre le taux de réussite des canulations entre le groupe VD seule et le groupe VD+VR (respectivement, $75 \%$ contre $85 \% ; P=0,65)$. Pour le groupe VD+VR, le temps nécessaire à la canulation IV au moment de la dernière tentative a été plus court par rapport au temps mis au cours de la première tentative $(P=0,002)$, ce qui n'a pas été le cas pour le groupe VD seule $(P=0,35)$.

Conclusion $L a$ vidéo de démonstration et la vidéo de rétroaction ont permis de raccourcir le temps de réalisation des habiletés d'une canulation IV, ont réduit les complications et amélioré la satisfaction des étudiants en médecine novices.
The optimal method of teaching and acquiring procedural skills is a contested area in medical education, where historically the "apprenticeship model" has been used. ${ }^{1-7}$ Feedback as a method of engaging learners ${ }^{8}$ has long been identified as an important component of learning in medical education. ${ }^{3,9}$ In healthcare learning, studies have shown that video feedback (VF), benchmarking, and modeling may be superior to traditional methods of verbal feedback alone. ${ }^{10-14}$

Video feedback occurs when learners watch videos of themselves performing skills, with or without expert audio annotation. Learners may watch these videos independently, or with an expert to provide concurrent guidance. This technique has contributed to the appraisal of procedural skill competence in medicine. ${ }^{10,12,15-18}$ The use of $\mathrm{VF}$ originated in athletics learning, ${ }^{19}$ which inspired robust literature supporting VF as an effective means of improving communication skills in healthcare education. $^{11,12,15,20-23}$ When applied to medical procedural skills, there are fewer studies that investigate its effectiveness as a procedural teaching tool. The Kirkpatrick model is a well-established educational model used to rank the impact of educational programs. ${ }^{24}$ In that model, there are four levels of learning evaluation: level 1 (reaction) evaluates how well a program was received, level 2 (learning) assesses skill acquisition, level 3 (transfer) determines whether the acquired skills change field behaviour, and level 4 (results) determines the final outcome (e.g., lower cost, higher efficiency). ${ }^{24}$ Current evidence robustly supports that VF improves learner satisfaction at level 1 (reaction), ${ }^{11,12,25-29}$ but there is a need to expand level 2 evidence (skill acquisition) in surgery ${ }^{30,31}$ and anesthesia learning. ${ }^{26,27}$

Video modeling (VM) is an alternate learning method that stems from behavioural research where learners watch videos of experts performing skills, providing a "perceptual blueprint" 32 activating "mirror neurons". 33 Observational practice provides unique opportunities to refine these skills and modify behaviour. ${ }^{34}$ Video modeling has been effective in improving athletic performance ${ }^{35}$ and laparoscopic skills. ${ }^{13}$

Video modeling and VF both have educational roots in deliberate practice, but in isolation from each other may not work as effectively. Deliberate practice involves focused repetitive practice for skill improvement, with feedback as the crux to augment clinical learning. ${ }^{1,3,36,37}$ During deliberate practice, VF can help to promote selfassessment as a source of feedback. ${ }^{1}$ Video modeling is also used in deliberate practice for learners to observe and analyze how experts perform at key decision points, assisted by external expert guidance. ${ }^{37}$ Some studies have not shown efficacy of $\mathrm{VF}^{28,29,35}$ or $\mathrm{VM},{ }^{38,39}$ possibly because interventions consisted of single practice 
sessions ${ }^{29,38,39}$ or long periods between sessions. ${ }^{28}$ These two methodologies combined (VM $+\mathrm{VF})$ may address a gap between observational learning, imitation, and selfassessment. ${ }^{19}$

A combination of $\mathrm{VM}$ and $\mathrm{VF}$ has been studied in athletics, ${ }^{19}$ with variable efficacy based upon activity type. $^{35,39,40}$ This combined technique has shown promising results in a small study of medical residents, showing improved hernia repair technique compared with traditional oral feedback. ${ }^{41}$ Nevertheless, this is the only medical procedural skills study to utilize this combined methodology.

No study to date has investigated the effects of combined VF + VM administered in a deliberate practice session with repetitive practice within a short time frame in novice learners. In the present study, we hypothesized that repeated VM with VF (group VM+VF) compared with repeated $\mathrm{VM}$ alone would reduce the time required for novice medical students to attempt peripheral IV cannulation.

\section{Methods}

\section{Recruitment}

This study was reviewed and approved by the Research Ethics Board at the University of Saskatchewan (Bio \# 15321, January 20 2016). The full study protocol can be reviewed at https://harvest.usask.ca/handle/10388/12454. This prospective, randomized, single-blind embedded mixed-methods study compared $\mathrm{VM}+\mathrm{VF}$ review to $\mathrm{VM}$ alone review (Fig. 1). A convenience sample of novice medical students was recruited as part of an extracurricular IV skills workshop between September 222016 and March 20 2017. Recruitment was accomplished through posters placed at the College of Medicine, University of Saskatchewan and distribution of an e-mail invitation to student class representatives. Learners that expressed interest provided written informed consent. Learners that had more than five prior experiences with IV cannulation were excluded.

\section{Pre-Test Survey}

We administered a pre-test survey gathering data on the participants' year of training, number of previous IV encounters, and any previous formal teaching they had received on IV cannulation, as well as the presence of any allergies to the local anesthetic Maxilene cream (RGR Pharma Ltd., LaSalle, ON, Canada) or medical conditions that would increase in risk by participation, such as bleeding conditions or active skin infections.

\section{Procedures}

Participants brought their own personal mobile device with video recording capabilities. If they did not possess one, a device was provided. We informed participants that they were being both audio and video recorded, and asked both facilitators and participants not to verbalize participant names during the procedure to maintain anonymity for data collection.

Participants received standardized instruction from a senior anesthesia resident facilitator or staff anesthesiologist facilitator on how to perform peripheral IV cannulation. A stepwise instructions list was provided to the facilitator beforehand that corresponded to a prepared expert video model for the study (Electronic Supplementary Material eVideo); facilitators were free to provide the instruction steps in their own words. The quality of the instruction was reinforced by the study investigator on the day of data collection, clarifying the instruction list and answering questions prior to study commencement. Instructional facilitators provided instruction to both groups. Both participants in an instructed pair could belong to either the same study group or a different study group. All facilitators provided instruction to participants in both groups.

Pretreatment with Maxilene cream was applied by the facilitators over what they judged would be feasible veins to perform cannulation; a minimum of 20 min elapsed prior to the intervention, allowing for full efficacy of the local anesthetic. Participants performed IV cannulation on each other as live models (with informed consent). At the time the research was performed, this form of paired practice was standard at this institution, as it allowed practical, realistic learning in a safe environment prior to patient encounters. All IV cannulation encounters were audio and video recorded. Only participants' hands were captured to preserve anonymity, and reasonable attempts were made to cover any distinctive markings still captured in the video (i.e., tattoos). Facilitators and participants were discouraged from using their names during video recording to avoid identification of the recorded participant.

All participants received concurrent verbal feedback in all groups as deemed appropriate by the facilitator during all encounters as per standard practice. This feedback was tailored to the needs of the participant at the discretion of the facilitator. Questions clarifying concurrent feedback and video modeling examples were permitted throughout the intervention period. A maximum of ten minutes was given to perform each IV encounter, which started at the beginning of skin puncture. Multiple attempts were permitted per encounter. The trial period ended with successful cannulation, as defined by: i) free blood 


\section{Study Design for Peripheral Intravenous Cannulation in Novice Medical Students}

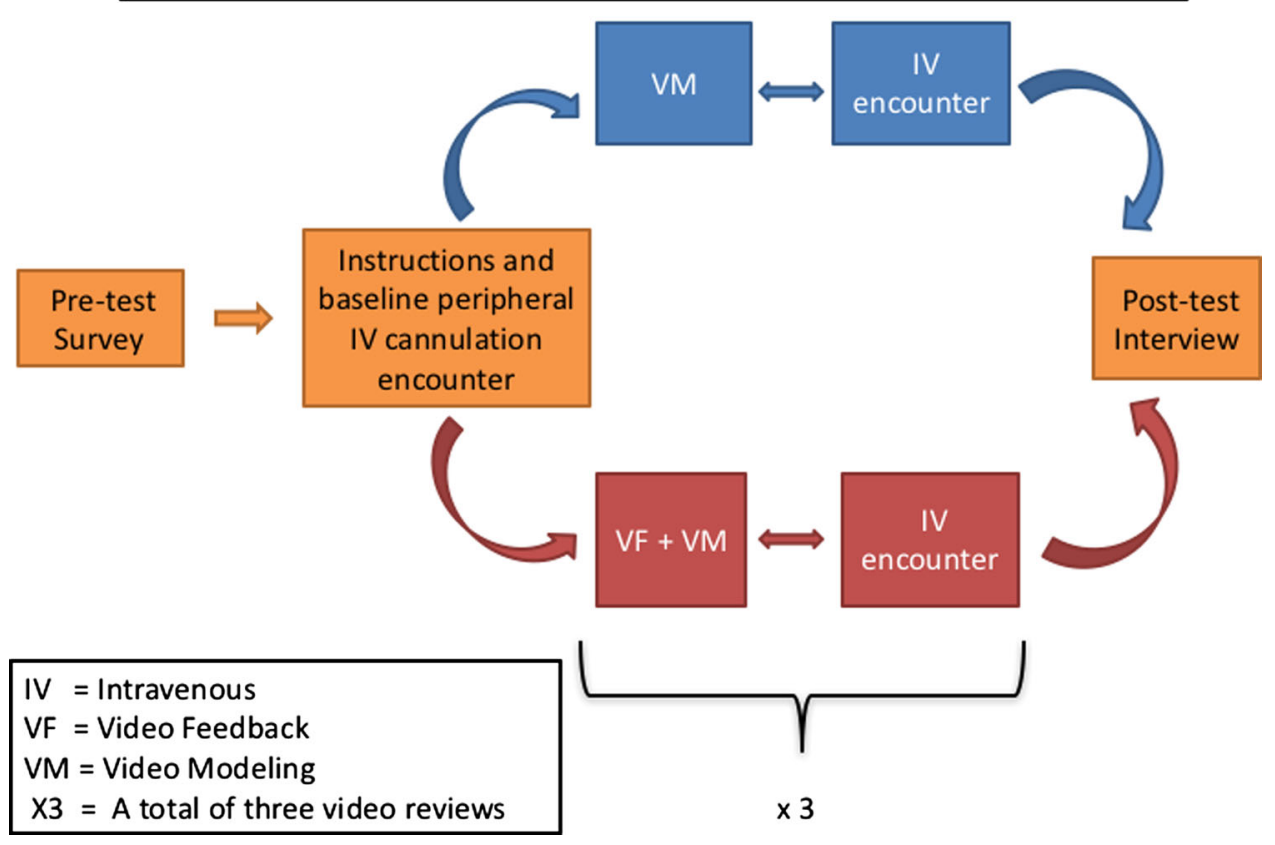

Fig. 1 Study design for peripheral intravenous (IV) cannulation in novice medical students. Participants received an entry survey and standardized instruction (shown in orange), and then performed IV cannulation on each other while being audio and video recorded. Participants were assigned to either groups that consisted of video modeling (VM) alone (shown in blue), or both VM and VF (video feedback) stated as VM+VF (shown in red) group. The VM alone

backflow into the cannula; ii) securing of the saline-locked IV tubing; and iii) patency confirmed by saline flush with lack of obvious extravasation. A failed encounter was determined by the inability to attain all three criteria in the same attempt after ten minutes, or if more than three attempts were required in one encounter. A single attempt was defined by skin puncture and removal of needle from skin. All encounters were done in a private, closed-door room.

Upon completion of each encounter, all participants were brought to a video review room. After the initial instruction and baseline IV encounter, each participant was randomly assigned by sealed envelope to one of two groups for the study by a study investigator: $\mathrm{VM}$ alone or $\mathrm{VM}+\mathrm{VF}$. Throughout the study, the participants remained assigned to these groups. The instructional facilitator was blinded to group assignment. Headphones were provided to the participants to facilitate audio review. Participants assigned to the VM alone group reviewed a video of an expert performing IV cannulation with audio narration explaining the steps (ESM eVideo). Participants assigned to the $\mathrm{VM}+\mathrm{VF}$ group reviewed the expert video, alongside their own most recent encounter at IV group reviewed an expert video performing IV cannulation, while the $\mathrm{VM}+\mathrm{VF}$ group reviewed the expert video and their own recent IV cannulation experience. Both groups (VM alone or $\mathrm{VM}+\mathrm{VF}$ ) then performed another IV cannulation. This was repeated for four IV cannulation encounters and three video reviews. A post-test interview was conducted (shown in orange) to assess participant satisfaction and this was analyzed qualitatively using thematic content analysis.

cannulation, which included the instructor feedback. Additional feedback was not given during video review. All participants in both groups were given ten minutes for the total video review period, even though the VM+VF group had more video material to review. They were allowed to fast forward or rewind any portion of the video review if so desired.

Participants then returned to the procedural room and performed IV cannulation again, with their new encounter video recorded. Upon completion of this second encounter, participants returned to the video review room. The VM alone group once again reviewed the expert video, whereas the $\mathrm{VM}+\mathrm{VF}$ group reviewed their newest recorded encounter alongside the expert video. This process was repeated to a total of four IV cannulation encounters and three audio-video review periods. Participants were free to withdraw or stop the intervention at any point in time. If participants felt lightheaded or unwell during the procedure, they were withdrawn by the investigators, and were welcome to be rescheduled if they so volunteered at a later date. Their respective partners were rescheduled at a later date when feasible. 


\section{Post-Test Interview and Qualitative Analysis}

Upon completion of four IV cannulation encounters and three audio-video review periods, each participant was individually interviewed by the primary author (J.Y.), and interviews were audio-recorded. Participants were asked the following questions to initiate and guide the interview in an open-ended fashion: 1) What was helpful about this learning experience with the video review? 2) What was not helpful or made the learning experience difficult with the video review? 3) Do you think the video review improved your learning experience: why or why not? and 4) How satisfied are you with the feedback you have received?

Qualitative data were analyzed using thematic content analysis to identify common patterns and themes in the manifest content of responses. ${ }^{42}$ Verbal interview data were managed reflexively and iteratively ${ }^{43}$ by: 1) audiotaping the interview and taking notes; 2) reflective journaling immediately post-interview; 3 ) listening to the audiotape and amending/revising field notes and observations; 4) preliminary content analysis; 5) secondary content analysis; and 6) thematic review. Themes were established by the primary author, then reviewed and refined through iterative discussions with co-authors (J.O.).

\section{Video Analysis}

The video recordings were analyzed by study authors blinded to group allocation after data were collected. To help preserve anonymity and avoid bias, no audio was reviewed for the purposes of analysis. The time stamp for initial skin puncture was zero seconds. The time stamp at successful cannulation, or the time of abandonment if the encounter was a failure, was recorded as the end time. The maximum time of abandonment was ten minutes. Successful or failed encounters were recorded. Complications were defined as: $>1$ attempts, hematoma formation, bleb formation from saline extravasation, inability to flush the cannula with saline, or removal of needle and/or cannula with no blood flow back into the hub. These were counted for each encounter and recorded.

\section{Outcomes}

The primary outcome measure was time required to perform IV cannulation during the final encounter. Secondary outcomes included the difference in time required to perform an IV cannulation encounter between baseline and final encounters within both groups, success percentage, number of IV complications (including $>1$ attempts), and what participants perceived to be subjectively helpful or not with their respective video reviews.

\section{Statistical Analysis}

The study data were analyzed for normality using the Kolmogorov-Smirnov test. Data presentation included the median [interquartile range (IQR)], unless otherwise described. A convenience sample size of 34 was utilized. The primary endpoint of final encounter times was compared between groups using the Mann-Whitney test. Baseline encounter times were also compared between groups using the Mann-Whitney test. Categorical secondary outcomes (e.g., success) was analyzed with Fisher's exact test, as two cells had an expected count $<5$. Continuous secondary outcomes (final $v s$ baseline encounter time) within each group were compared with Wilcoxon signed rank test. The between group and within group median differences (e.g., encounter time, $>1$ insertion attempts, complications) were estimated with Hodges-Lehman median difference, and corresponding 95\% confidence intervals $(\mathrm{CI})$ were calculated. A $P<0.05$ was considered statistically significant. No correction for multiplicity was performed. Statistical analysis was performed using IBM SPSS v25 (IBM Corp., Armonk, NY, USA).

\section{Results}

Thirty-four participants volunteered for this study. Nine participants' data were not included in our analysis including two participants who were part of an initial pilot trial run with flaws in study conduction, four participants who felt lightheaded during the initial procedural intervention, and three participants who could not be scheduled. Thus, 25 participants were analyzed in our final sample: 12 participants in the VM alone group, and 13 in the VM+VF group. These participants' baseline experience in IV cannulation is shown in Table 1. There were no meaningful demographic differences between groups. Of interest, two participants stated they had previous IV cannulation experience, but did not meet exclusion criteria of five previous IV attempts or more. One participant elaborated in the pre-test survey:

"[During a] skills [training] day in Regina, I had the opportunity to watch someone put an IV in and try one myself." 
Table 1 Baseline demographics and education experience from pretest survey

\begin{tabular}{|c|c|c|}
\hline & $\begin{array}{l}\text { VM } \\
\text { alone } \\
n=12\end{array}$ & $\begin{array}{l}\mathrm{VM}+\mathrm{VF} \\
n=13\end{array}$ \\
\hline Year of training in medical school & $2[1-2]$ & $1[1-2]$ \\
\hline Previous intravenous encounters & $0[0-1]$ & $0[0-0]$ \\
\hline $\begin{array}{l}\text { Participants with prior intravenous cannulation } \\
\text { training }\end{array}$ & 2 & 0 \\
\hline
\end{tabular}

Data are presented as median [interquartile range].

$\mathrm{VF}=$ video feedback. $\mathrm{VM}=$ video modeling .

\section{Quantitative Data}

Primary and secondary outcomes in unpaired analysis are shown in Table 2. There were no significant differences in median time required for IV cannulation at baseline between the two groups $(P=0.70)$. Comparing the primary outcome, the median $[\mathrm{IQR}]$ time required to perform IV cannulation in the final encounter was significantly different between the $\mathrm{VM}+\mathrm{VF}$ group $v s \mathrm{VM}$ alone group (126 [133] sec vs 345 [406] sec, respectively; median difference, $111 \mathrm{sec} ; 95 \% \mathrm{CI}, 8$ to $391 ; P=0.02$ ). The percentage of successful IV cannulation for the two groups (VM alone $v s \mathrm{VM}+\mathrm{VF}$ ) was not significantly different $(P=0.65)$ (Table 2). The difference in time required to perform successful IV cannulation between final and baseline encounters within the VM alone group and the VM+VF group is shown in Fig. 2.
Paired-related analysis of participants attempts (i.e., final $v$ s baseline within groups) was also performed. For the $\mathrm{VM}+\mathrm{VF}$ group, the median [IQR] time to perform IV cannulation in the final encounter was lower after intervention compared with baseline values (126 [93-226] sec vs 465 [339-610] sec, respectively; median difference, $284 \mathrm{sec} ; 95 \%$ CI, 124 to $439 ; P=0.002$ ). Conversely, when these values were measured for the VM alone group, the time to perform IV cannulation in the final encounter was not significantly lower compared with baseline values (345 [131-537] sec vs 418 [365-598] sec, respectively; median difference, $63 \mathrm{sec} ; 95 \% \mathrm{CI},-67$ to $260 ; P=0.35$ ).

A comparison of related samples was also performed for complications. For the VM+VF group, there was a significant reduction in the median [IQR] number of complications when comparing final to baseline encounters (0 [0-1], vs 3 [0-4], respectively; median difference, 1.5; 95\% CI, 0 to $2.5 ; P=0.02$ ). There was no significant difference in the number of complications between final and baseline encounters within the VM alone group (2 [03] vs 2.5 [1.5-3.3], respectively; median difference, 0.5; $95 \% \mathrm{CI},-0.5$ to $2 ; P=0.17$ ).

A further analysis was performed specifically on $>1$ IV attempts within each group. In the VM+VF group, there was no significant reduction in the median [IQR] number of attempts $>1$ when comparing their final encounter to their baseline encounter $(0$ [0-1] vs 1[ 0-2], respectively; median difference $0.5 ; 95 \% \mathrm{CI}, 0$ to $1 ; P=0.10$ ). Similarly, there was no difference in the VM alone group when comparing their final encounter to their baseline encounter

Table 2 Analysis of primary and secondary quantitative outcomes between groups

\begin{tabular}{|c|c|c|c|c|}
\hline & VM alone & $\mathrm{VM}+\mathrm{VF}$ & Median difference, $95 \% \mathrm{CI}^{\mathrm{c}}$ & $P$ value \\
\hline \multicolumn{5}{|l|}{ Primary outcome } \\
\hline \multicolumn{5}{|l|}{ Time required to perform IV cannulation (sec) } \\
\hline baseline & $418[365-598]$ & $465[339-610]$ & $-18.5,-186$ to $130^{\mathrm{c}}$ & $0.70^{\mathrm{a}}$ \\
\hline final & 345 [131-537] & $126[93-226]$ & $111,8-391^{\mathrm{c}}$ & $\mathbf{0 . 0 2} 2^{\mathrm{a}}$ \\
\hline$\Delta$ (final - baseline $)$ & $-44[-225$ to 71$]$ & $-216[-484$ to -104$]$ & $184,184-421^{\mathrm{c}}$ & $0.04^{\mathrm{a}}$ \\
\hline \multicolumn{5}{|l|}{ Secondary outcomes } \\
\hline Success of final encounter, $n /$ total $\mathrm{N}(\%)$ & $9 / 12(75 \%)$ & $11 / 13(85 \%)$ & & $0.65^{\mathrm{b}}$ \\
\hline Number of attempts $>1$ in final encounter & $1[0-1]$ & $0[0-1]$ & $0[0-1]$ & $0.38^{\mathrm{a}}$ \\
\hline
\end{tabular}

Statistically significant $P$ values are highlighted in bold.

Data are presented as median [interquartile range].

a Mann-Whitney test

b Fisher's exact test

c Hodges-Lehman estimator

$\mathrm{CI}=$ confidence interval; $\mathrm{IV}=$ intravenous; $\mathrm{VF}=$ video feedback. $\mathrm{VM}=$ video modeling. 
(1 [0-1.3] vs 1 [0.8-2], respectively; median difference, 0.5 ; 95\% CI, 0 to $1 ; P=0.12$ ).

Qualitative Data

\section{Video Modeling: Schema Solidification}

Participants perceived an overwhelming value of VM in general, as it assisted with learning schema, as suggested by ten participants. Participants believed that the first and second video review periods, in conjunction with concurrent in-task facilitator instruction, helped to solidify the verbal instruction. It allowed an opportunity to review specific steps that were more challenging than others. As stated by two participants, VM was helpful:

“...between the first and second (reviews)... because

I could re-watch it a bunch of times and really cement

it in my head...repetition was good."

Participants found VM also allowed for a period of reflection on practice, when mentally comparing their previous encounter with the current model.

"you notice different things that you might (want to) try to improve, every time I watch the (model) video."

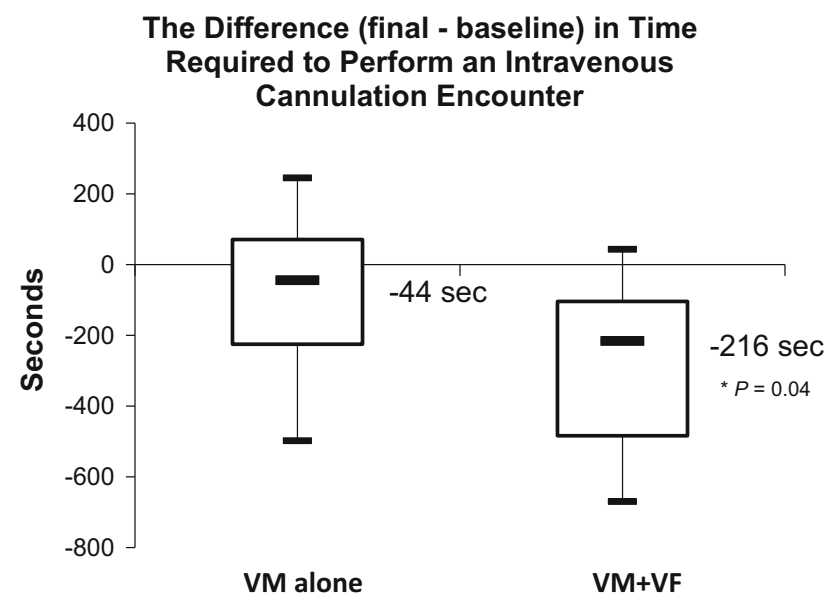

Fig. 2 The difference in time required to perform an intravenous (IV) cannulation encounter for two groups (VM alone or VM+VF). The results were calculated by taking the time it took each participant to perform their baseline IV cannulation subtracted from the time it took each participant to complete their paired final cannulation. This is stated as "final - baseline". Negative numbers represent a reduction in time required for a participant to complete the IV encounter. The medians are statistically significantly different $(P=0.04)$. The bold line represents the median. The box lower and upper parameters represent the first and third quartiles respectively. The upper and lower whisker represent the minimum and maximum values, respectively. $\mathrm{VF}=$ video feedback. $\mathrm{VM}=$ video modeling. $* P=0.04$
Video Modeling: Limited Educational Tool

Nine participants felt that, while useful in this initial review period, repetition of the same model content had yielded reduced utility as the session proceeded. As summarized by one participant:

"I was just repeating the one part again and again...by the time it hit the third review, I was like, 'nah, I got it'...I needed my own personal experience of it in order to learn further, didn't think the video could offer me more at that point"

There were concerns regarding the lack of depth and detail of standardized VM, which meant it was unable to address specific learning objectives that some participants struggled with more than others. One participant stated:

"It [video modeling] doesn't help when you're stuck and you don't know what you're doing wrong... I thought I needed more guidance than just watching a video (model) could provide."

Where some felt the video was the appropriate duration, others felt it was not slow enough. Overall, however, participants also felt any deficiencies were well-addressed during the instructor facilitation.

\section{Video Feedback: Expert Audio-Guided Reflection on Practice}

Seven participants felt strongly that audio review of the facilitator feedback in conjunction to the video review was integral to the utility of this learning method. Multiple learners felt it allowed for another opportunity to better perceive and understand what their instructors had observed, in a safe environment. Participants commented:

“it was helpful to go back... [the instructor's] feedback was on there [in audio], so I could listen to what I was doing and what needed to be changed, so I could listen to that again, because if it's only happening once, it washes over you, so it kind of got ingrained a little bit more."

"I could review what I had done, without the additional stress of hurting someone (in the moment)"

\section{Video Feedback: Inferiority to Concurrent Feedback}

Some participants felt the strength of the concurrent feedback in its nature by being direct, timely, and specific, was superior to VF or VM. With each video period taking up to ten minutes, some learners felt it took 
too long to go through an unhelpful review. One participant felt that rather than an interrupting review, they would have found it more useful to continue practice with facilitator guidance. Being able to ask questions to clarify concepts in a timely fashion was considered valuable. One participant even stated:

"I would have preferred to just ... have the one on one coaching. ... I just wanted to keep practicing without the interruption [of the video review]."

\section{Video Modeling and Video Feedback: Combined Modalities of Learning}

Video modeling $+\mathrm{VF}$ activated multiple different modalities of learning, including kinetic, visual, and auditory, which two participants specifically found helpful.

"I got all different types of learning, I got verbally, I got ... to actually do it physically, and then I got to see. So the video review was really good because I [was not] just abstract thinking 'oh what am I doing'?"

"...it was another form of learning that I was exposed to...the visual and auditory stimulus, and then going back and doing the tactile, kinesthetic learning."

\section{Study Design}

Some participant comments specifically addressed issues of study design. One individual found value in paired practice, where their partner was able to give them feedback on how an IV felt, and how their attempt compared with their partner's. The pain of previous IV attempts was distracting for some. Others felt that the lack of in vivo demonstration or of VM prior to their first encounter impeded their ability to perform well. Additionally, one person felt that deviation between video model instructions and facilitator instruction distracted them from overall learning.

\section{Discussion}

This study showed that the $\mathrm{VM}+\mathrm{VF}$ group required less time to perform IV cannulation than the VM alone group. Qualitative analysis suggested both visual and audio reviews of both expert and self-performance were integral to maximizing procedural learning. Participants attributed success to the ability to reflect on their previous encounter. While VM+VF was perceived as inferior to in vivo preceptorship, $\mathrm{VM}+\mathrm{VF}$ provides a viable alternative where direct preceptorship is not possible.
There has been conflicting evidence in the literature regarding procedural learning using VF. Video feedback has improved epidural performance, with an anesthesiologist guiding the review. ${ }^{26}$ Conversely, visualonly video review of laryngoscopy attempts did not improve performance. ${ }^{44}$ This variability in efficacy might be explained by the lack of audio-guided expert review post-intervention, which may be a necessary component that was not previously appreciated. Review of the same concurrent verbal feedback can be received differently when reviewed after a procedural attempt. Previous studies have shown differences in learning retention when comparing in-task feedback to end-task feedback. ${ }^{45}$ Differences in stress in-task, which are not well replicated by simulated environments, ${ }^{46}$ may explain the differences in feedback processing.

Despite showing a difference in time to task completion, we did not show a difference in overall success percentage. This is not surprising and is consistent with existing reports looking at binary outcomes of success. For example there was no difference in binary-scored suturing performance of medical students with expert guided VF compared with unguided VF. ${ }^{31}$ Because small sample sizes may not be not well powered to observe for overall binary success or failure, time to completion has often been used as a surrogate for proficiency in other VF studies in skill mastery, ${ }^{4,47}$ and may better capture nuances in early learning by encompassing multiple aspects of task efficiency and performance.

The superior learning effect seen with combined $\mathrm{VM}+\mathrm{VF}$ in our study may be secondary to repeated audio review, which is consistent with the principles of deliberate practice. Deliberate practice originates from the concept of attaining maximal level of performance through deliberate efforts rather than unfocused extended experience. Ericsson et al. defined the conditions under which deliberate practice occurs-i.e., it transpires when there is a focused goal, with intention to improve, with provided feedback, and with opportunity for refinement. $^{36,48}$ Pusic et al. reinforce the concept of "sequential, mindful repetitions of a training task, along with immediate feedback, such that expert performance is acquired gradually". 49 The learner adjusts and makes changes relevant for improvement before engaging in the next cycle of practice. In the current study, both groups had a well-defined goal demonstrated in the expert video, as well as specific and immediate concurrent feedback. Nevertheless, where VM+VF may have been superior is by providing an additional source of audio-video feedback during video review, facilitating further self-reflection at end-task prior to the next cycle of practice. The VM group on the other hand required the learner to expend more 
effort self-reflecting based upon memory of the events and feedback of the prior practice cycle.

Previously, the "apprenticeship model" was the most common teaching model used for clinical procedures in undergraduate medical education, ${ }^{50-52}$ contributing to long work hours. Recent trends limiting resident work hours reduce direct trainee-trainer interactions, and may have significant implications on skill development. Apprenticeship is therefore supplemented with focused clinical teaching environments. ${ }^{51}$ Trainee-centred models are recommended to focus on specific learner needs from observation of a clinical interaction. ${ }^{51,53}$ The effectiveness of VM+VF compared with VM alone highlights the benefit of trainee-specific feedback. In the era of competencybased medical education, methods utilizing trainee-specific feedback, such as the one described, may enhance the effectiveness of focused clinical learning.

The strengths of this study are multifold. First, this study shows the feasibility of an easily translatable learning method. Video technology is ubiquitous, and allows a learner to maximize existing learning opportunities. Second, this study used paired analysis of participants on themselves, accounting for learner variability. Vein anatomic variability (e.g., adiposity, skin tone) was partially controlled by having participants practice on the same partner. Anatomic difficulty may even have escalated, with easier veins used first, and more difficult veins reserved for later. Third, this study protocol examined novice learners in the context of intensive, repetitive practice, in a focused and supervised workshop within a short time frame, which can easily be incorporated into a structured curriculum. Fourth, this was an embedded mixed-method study, with primary quantitative data collection and subsequent qualitative data collection that allowed robust analysis of the experience. The combination of these data show both Kirkpatrick level 1 and level 2 evidence, a well-received intervention, and skill improvement.

The limitations of this study include a small sample size that may not represent the true breadth of learners, given that keen volunteers seeking additional experience don't necessarily represent all learners. Additionally, the effectiveness of $\mathrm{VM}+\mathrm{VF}$ is less clear in high acuity low occurrence procedures, or of more complex procedures. Lastly, because of study design, the skill was not demonstrated in a high-fidelity model prior to baseline encounter, potentially rendering it unrealistically challenging. This, however, may reflect clinical encounters at the bedside, where high-fidelity model observation is not always possible.

Future research could test VM $+\mathrm{VF}$ in the acquisition of other complex procedural skills, or in more advanced learners. Participants suggested that skill refinement was better developed with $\mathrm{VM}+\mathrm{VF}$ in later repetitions; a similar phenomenon may be observed with experienced learners looking to refine mastery of skill sets. Other future studies may include assessing for learning curves, and teaching efficacy over traditional means. Additionally, while this study has increased level 1 and level 2 evidence, a follow up study to assess for Kirkpatrick level 3 transfer evidence may be warranted.

\section{Conclusions}

In this small study, VM+VF shortened time to skill completion and reduced complications in novice learners, but did not improve success. It is a ubiquitous technology that can be immediately applied in current clinical learning environments to maximize learning and allow for later independent or mentored review.

Author contributions Julie $Y u$ contributed to all aspects of this manuscript, including study conception and design; acquisition, analysis, and interpretation of data; and drafting the article. Calvin Lo contributed to data acquisition and interpretation of data. Claudia Madampage contributed to the drafting of the manuscript. Jagmeet Bajwa contributed to the analysis of data. Jennifer O'Brien contributed to study conception and design, as well as analysis and interpretation of data. Paul Olszynski contributed to study conception and design. Malcolm Lucy contributed to study conception and design, and acquisition and interpretation of data. All authors contributed to the critical revision of the manuscript.

Acknowledgements The authors wish to thank the Clinical Learning Resource Centre staff, the anesthesia residents at the University of Saskatchewan, and the late Dr. Neil Cowie. Without all of their support, this project would never have been possible.

\section{Conflicts of interest None.}

Funding statement The authors wish to thank the Department of Anesthesia for their generous funding of the project, the Clinical Learning Resource Centre for their generous equipment contributions, as well as the in-kind equipment support received from the following: ICU Medical, B.D. Posi Flush, Rit Med, 3-M, Hospira.

Ethical approval Ethical approval for studies on human subjects was granted by the Biomedical Research Ethics Board (Bio-REB) at the University of Saskatchewan on Jan 20 2016, Bio \# 15-321.

Editorial responsibility This submission was handled by Dr. Hilary P. Grocott, Editor-in-Chief, Canadian Journal of Anesthesia.

\section{References}

1. Hastings RH, Rickard TC. Deliberate practice for achieving and maintaining expertise in anesthesiology. Anesth Analg 2015; 120: 449-59. 
2. Grantcharov TP, Reznick RK. Teaching procedural skills. BMJ 2008; 336: 1129-31.

3. Issenberg SB, McGaghie WC, Petrusa ER, Lee Gordon D, Scalese RJ. Features and uses of high-fidelity medical simulations that lead to effective learning: a BEME systematic review. Med Teach 2005; 27: 10-28.

4. Broking $K$, Waurick $R$. How to teach regional anesthesia. Curr Opin Anaesthesiol 2006; 19: 526-30.

5. Ashley EA. Medical education - beyond tomorrow? The new doctor - Asclepiad or Logiatros? Med Educ 2000; 34: 455-9.

6. Castanelli DJ. The rise of simulation in technical skills teaching and the implications for training novices in anaesthesia. Anaesth Intensive Care 2009; 37: 903-10.

7. Gardner H. Frames of Mind: The Theory of Multiple Intelligences. NY: Basic Books; 2011 .

8. Kolb AY, Kolb DA. Learning styles and learning spaces: enhancing experiential learning in higher education. Acad Manag Learn Educ 2005; 4: 193-212.

9. Ende J. Feedback in clinical medical education. JAMA 1983; 250: 777-81.

10. Colthart I, Bagnall G, Evans A, et al. The effectiveness of selfassessment on the identification of learner needs, learner activity, and impact on clinical practice: BEME Guide no. 10. Med Teach 2008; 30: 124-45.

11. Yoo MS, Chae SM. Effects of peer review on communication skills and learning motivation among nursing students. J Nurs Educ 2011; 50: 230-3.

12. Lane $J L$, Gottlieb RP. Improving the interviewing and selfassessment skills of medical students: is it time to readopt videotaping as an educational tool? Ambul Pediatr 2004; 4: 2448.

13. Stefanidis D, Korndorffer JR Jr, Heniford BT, Scott DJ. Limited feedback and video tutorials optimize learning and resource utilization during laparoscopic simulator training. Surgery 2007; 142: 202-6.

14. Stranc MF, McDiarmid JG, Stranc LC. Video assessment of surgical technique. Br J Plast Surg 1991; 44: 65-8.

15. Yoo MS, Son YJ, Kim YS, Park JH. Video-based self-assessment: implementation and evaluation in an undergraduate nursing course. Nurse Educ Today 2009; 29: 585-9.

16. Martin D, Regehr G, Hodges B, McNaughton N. Using videotaped benchmarks to improve the self-assessment ability of family practice residents. Acad Med 1998; 73: 1201-6.

17. Ward M, MacRae H, Schlachta C, et al. Resident self-assessment of operative performance. Am J Surg 2003; 185: 521-4.

18. Jamshidi R, LaMasters T, Eisenberg D, Duh QY, Curet $M$. Video self-assessment augments development of videoscopic suturing skill. J Am Coll Surg 2009; 209: 622-5.

19. Liebermann DG, Katz, L, Hughes MD, Bartlett RM, McClements $J$, Franks IM. Advances in the application of information technology to sport performance. J Sports Sci 2002; 20: 755-69.

20. Crenshaw JT. Use of video-feedback, reflection, and interactive analysis to improve nurse leadership practices. Nurs Adm Q 2012; 36: 260-7.

21. Roter DL, Larson $S$, Shinitzky $H$, et al. Use of an innovative video feedback technique to enhance communication skills training. Med Educ 2004; 38: 145-57.

22. Paul S, Dawson KP, Lanphear JH, Cheema MY. Video recording feedback: a feasible and effective approach to teaching historytaking and physical examination skills in undergraduate paediatric medicine. Med Educ 1998; 32: 332-6.

23. Ozcakar N, Mevsim V, Guldal D, et al. Is the use of videotape recording superior to verbal feedback alone in the teaching of clinical skills? BMC Public Health 2009. https://doi.org/10.1186/ 1471-2458-9-474.
24. Kirkpatrick D. Revisiting Kirkpatrick's four-level-model. Train Dev 1996; 1: 54-7.

25. Nesbitt C, Phillips AW, Searle R, Stansby G. Student views on the use of 2 styles of video-enhanced feedback compared to standard lecture feedback during clinical skills training. J Surg Educ 2015; 72: 969-73.

26. Birnbach DJ, Santos AC, Bourlier RA, et al. The effectiveness of video technology as an adjunct to teach and evaluate epidural anesthesia performance skills. Anesthesiology 2002; 96: 5-9.

27. Kardash $K$, Tessler MJ. Videotape feedback in teaching laryngoscopy. Can J Anaesth 1997; 44: 54-8.

28. Backstein D, Agnidis Z, Sadhu R, MacRae H. Effectiveness of repeated video feedback in the acquisition of a surgical technical skill. Can J Surg 2005; 48: 195-200.

29. Backstein D, Agnidis $Z$, Regehr G, Reznick R. The effectiveness of video feedback in the acquisition of orthopedic technical skills. Am J Surg 2004; 187: 427-32.

30. Farquharson AL, Cresswell AC, Beard JD, Chan P. Randomized trial of the effect of video feedback on the acquisition of surgical skills. Br J Surg 2013; 100: 1448-53.

31. Nesbitt CI, Phillips AW, Searle RF, Stansby G. Randomized trial to assess the effect of supervised and unsupervised video feedback on teaching practical skills. J Surg Educ 2015; 72: 697-703.

32. Sheffield FD. Theoretical considerations in the learning of complex sequential tasks from demonstration and practice. In: Lumsdaine AA (Ed.). Student Response in Programmed Instruction. Washington, DC: National Academy of SciencesNational Research Council; 1961: 13-32.

33. Cross ES, Kraemer DJ, de C Hamilton AF, Kelley WM, Grafton $S T$. Sensitivity of the action observation network to physical and observational learning. Cereb Cortex 2009; 19: 315-26.

34. Wulf $G$, Shea $C$, Lewthwaite $R$. Motor skill learning and performance: a review of influential factors. Med Educ 2010; 44: 75-84.

35. Zetou E, Tzetzis G, Vernadakis N, Kioumourtzoglou E. Modeling in learning two volleyball skills. Percept Mot Skills 2002; 94(3 Pt 2): 1131-42.

36. Ericsson KA, Krampe RT, Tesch-Römer C. The role of deliberate practice in the acquisition of expert performance. Psychol Rev 1993; 100: 363-406.

37. Ericsson KA. Necessity is the mother of invention: video recording firsthand perspectives of critical medical procedures to make simulated training more effective. Acad Med 2014; 89 : 17-20.

38. Miller G, Gabbard $C$. Effects of visual aids on acquisition of selected tennis skills. Percept Mot Skills 1988; 67: 603-6.

39. Barzouka K, Bergeles $N$, Hatziharistos D. Effect of simultaneous model observation and self-modeling of volleyball skill acquisition. Percept Mot Skills 2007; 104: 32-42.

40. Boyer E, Miltenberger RG, Batsche C, Fogel V. Video modeling by experts with video feedback to enhance gymnastics skills. J Appl Behav Anal 2009; 42: 855-60.

41. Cauraugh JH, Martin M, Martin KK. Modeling surgical expertise for motor skill acquisition. Am J Surg 1999; 177: 331-6.

42. Simons L, Lathlean J, Squire C. Shifting the focus: sequential methods of analysis with qualitative data. Qual Health Res 2008; 18: $120-32$.

43. Halcomb EJ, Davidson PM. Is verbatim transcription of interview data always necessary? Appl Nurs Res 2006; 19: 38-42.

44. Sainsbury JE, Telgarsky B, Parotto M, Niazi A, Wong DT, Cooper RM. The effect of verbal and video feedback on learning direct laryngoscopy among novice laryngoscopists: a randomized pilot study. Can J Anesth 2017; 64: 252-9.

45. Lean $L L$, Hong $R Y, T i L K$. End-task versus in-task feedback to increase procedural learning retention during spinal anaesthesia 
training of novices. Adv Health Sci Educ Theory Pract 2017; 22: 713-21.

46. Baker BG, Bhalla A, Doleman B, et al. Simulation fails to replicate stress in trainees performing a technical procedure in the clinical environment. Med Teach 2017; 39: 53-7.

47. Carter SC, Chiang A, Shah G, et al. Video-based peer feedback through social networking for robotic surgery simulation: a multicenter randomized controlled trial 2015; 261: 870-5.

48. Ericsson KA. Deliberate practice and acquisition of expert performance: a general overview. Acad Emerg Med 2008; 15: 988-94.

49. Pusic M, Pecaric M, Boutis K. How much practice is enough? Using learning curves to assess the deliberate practice of radiograph interpretation. Acad Med 2011; 86: 731-6.
50. Dornan T. Osler, Flexner, apprenticeship and 'the new medical education'. J R Soc Med 2005; 98: 91-5.

51. Wynne K. Death of the physician apprentice. BMJ 2009. https:// doi.org/10.1136/bmj.b2994.

52. Thompson L, Exline M, Leung CG, et al. A clinical procedures curriculum for undergraduate medical students: the eight-year history of a third-year immersive experience. Med Educ Online 2016. https://doi.org/10.3402/meo.v21.29486.

53. Irby DM, Wilkerson L. Teaching when time is limited. BMJ 2008; 336: $384-7$

Publisher's Note Springer Nature remains neutral with regard to jurisdictional claims in published maps and institutional affiliations. 